\title{
Multimodal Imaging in Neurofibromatosis Type 1- associated Nerve Sheath Tumors
}

\section{Multimodale Bildgebung bei Neurofibromatose-Typ-1-asso- ziierten Nervenscheidentumoren}

Authors

Affiliations
J. Salamon ${ }^{1}$, V. F. Mautner², G. Adam¹, T. Derlin ${ }^{3}$

Department of Diagnostic and Interventional Radiology, University Medical Center Hamburg-Eppendorf, Hamburg, Germany

2 Department of Neurology, University Medical Center Hamburg-Eppendorf, Hamburg, Germany

Department of Nuclear Medicine, Hannover Medical School, Hannover, Germany

\author{
Key words \\ NF1 \\ - neurofibromatosis \\ - MPNST \\ - MRI \\ - PET
}

received $\quad 12.3 .2015$ accepted 25.6.2015

Bibliography

DOI http://dx.doi.org/ 10.1055/s-0035-1553505

Published online: 2.9 .2015

Fortschr Röntgenstr 2015; 187: 1084-1092 @ Georg Thieme Verlag KG Stuttgart · New York . ISSN 1438-9029

\footnotetext{
Correspondence

Dr. Johannes Salamon

Klinik und Poliklinik für

Diagnostische und

Interventionelle Radiologie,

Universitätsklinikum Hamburg-

Eppendorf

Martinistraße 52

20246 Hamburg

Germany

Tel.: ++ 49/0 40/741054029

Fax: ++49/0 40/7 41053802

j.salamon@uke.de
}

\section{Abstract \\ $\nabla$}

Neurofibromatosis type 1 (NF1) is a neurogenetic disorder. Individuals with NF1 may develop a variety of benign and malignant tumors of which peripheral nerve sheath tumors represent the most frequent entity. Plexiform neurofibromas may demonstrate a locally destructive growth pattern, may cause severe symptoms and may undergo malignant transformation into malignant peripheral nerve sheath tumors (MPNSTs). Whole-body magnetic resonance imaging (MRI) represents the reference standard for detection of soft tissue tumors in NF1. It allows for identification of individuals with plexiform neurofibromas, for assessment of local tumor extent, and for evaluation of whole-body tumor burden on T2-weighted imaging. Multiparametric MRI may provide a comprehensive characterization of different tissue properties of peripheral nerve sheath tumors, and may identify parameters associated with malignant transformation. Due to the absence of any radiation exposure, whole-body MRI may be used for serial follow-up of individuals with plexiform neurofibromas. ${ }^{18} \mathrm{~F}$-fluorodeoxyglucose positron-emission-tomography (FDG PET/CT) allows a highly sensitive and specific detection of MPNST, and should be used in case of potential malignant transformation of a peripheral nerve sheath tumor. PET/CT provides a sensitive whole-body tumor staging. The use of contrast-enhanced CT for diagnosis of peripheral nerve sheath tumors is limited to special indications. To obtain the most precise readings, optimized examination protocols and dedicated radiologists and nuclear medicine physicians familiar with the complex and variable morphologies of peripheral nerve sheath tumors are required.
Key points:

- Individuals with NF1 may develop benign and malignant nerve sheath tumors.

- Whole-body MRI is the reference standard to identify nerve sheath tumors in NF1.

- MRI provides a comprehensive characterization of the growth pattern, growth dynamics and extent of nerve sheath tumors.

- ${ }^{18} \mathrm{~F}$-FDG PET/CT provides a sensitivity of $100 \%$ and a specificity of $77-95 \%$ for detection of malignant transformation.

Citation Format:

- Salamon J, Mautner VF, Adam G et al. Multimodal Imaging in Neurofibromatosis Type 1-associated Nerve Sheath Tumors. Fortschr Röntgenstr 2015; 187: 1084-1092

\section{Zusammenfassung}

$\nabla$

Die Neurofibromatose Typ 1 (NF1) ist eine neurogenetische Erkrankung, die mit der Entwicklung unterschiedlicher benigner und maligner Tumoren einhergeht, wobei periphere Nervenscheidentumoren die häufigste Entität darstellen. Plexiforme Neurofibrome können lokal destruktiv wachsen, eine ausgeprägte Symptomatik verursachen und unterliegen dem Risiko einer malignen Transformation in maligne periphere Nervenscheidentumoren (MPNST). Die Ganzkörper-Magnetresonanztomografie (MRT) stellt den Referenzstandard zur Detektion von Weichteiltumoren bei NF1 dar und erlaubt die Identifikation von Individuen mit plexiformen Neurofibromen, eine Erfassung der lokalen Tumorausbreitung und die Bestimmung der Ganzkörpertumorlast in T2-gewichteten Sequenzen. In der multiparametrischen MRT kann eine umfassende Charakterisierung der Gewebeeigenschaften von peripheren Nervenscheidentumoren erfolgen; zudem können auf MPNST hinweisende Parameter sensitiv erfasst werden. Aufgrund der fehlenden Strahlenexposi- 
tion eignet sich die Ganzkörper-MRT für serielle Verlaufskontrollen bei Patienten mit plexiformen Neurofibromen. Die ${ }^{18} \mathrm{~F}$-Fluordesoxyglukose-Positronen-Emissions-Tomografie (FDG PET/CT) erlaubt eine hochsensitive und spezifische Detektion von MPNST und sollte beim Verdacht auf eine maligne Transformation eines Nervenscheidentumors eingesetzt werden. Dadurch erfolgt gleichzeitig ein sensitives Ganzkörperstaging. Die alleinige kontrastmittelgestützte CT ist heutzutage in der Diagnostik peripherer Nervenscheidentumoren nur noch in Sondersituationen indiziert. Für eine optimale Diagnostik bei Individuen mit NF1 sollten spezifische Untersuchungsprotokolle eingesetzt werden, und Radiologen und Nuklearmediziner sollten mit der komplexen und variablen Morphologie peripherer Nervenscheidentumoren vertraut sein.

\section{Introduction}

Neurofibromatosis type 1 (NF1, von Recklinghausen's disease) is an autosomal-dominant hereditary neurogenic disease with an incidence of 1:2500-1:3000 [1, 2]. However, roughly $50 \%$ of affected individuals develop NF1 through a de novo mutation. The first in-depth clinical description of NF1 was published by Friedrich Daniel von Recklinghausen in 1882 [3], and standardized clinical diagnostic criteria have existed since 1987 ( $\bullet$ Tab. 1) [4], with genetic analysis - at least for diagnostic purposes - being required only in special cases.

The clinical appearance of NF1 is characterized by wide variability [5, 6]. Cutaneous clinical characteristics of NF1 include café-au-lait spots (light brown hyperpigmentation with smooth borders), axillary as well as inguinal freckling (freckle-like hyperpigmentation in areas usually not exposed to the sun) and Lisch nodules (benign iris hamartoma) [7-10]. Musculoskeletal abnormalities are frequently observed and include scoliosis (in 10-20\% of individuals), osteoporosis with significantly elevated risk of fractures, pseudoarthrosis and diagnostically revealing deformations such as congenital sphenoid wing dysplasia and tibial dysplasia $[6,7,11,12]$. Common cardiovascular manifestations are a frequent arterial hypertension, hypertrophic cardiomyopathies, pulmonary artery stenosis and other congenital heart defects as well as NF1-associated vasculopathy with stenosis of the renal and cerebral arteries [6, 13, 14]. Central neurocognitive deficits such as visuomotor impairments are a common neurological symptom of NF1. For example, approximately $53 \%$ of children with NF have poor handwriting versus only $6 \%$ of children in the comparative population. Approximately $39 \%$ of children with NF1 have learning disabilities. There are also behavioral disorders and intellectual disabilities. For example, $6-7 \%$ of children with NF1 have an IQ below 70 versus $2 \%$ of the normal population, and up to $49.5 \%$ of children with NF1 develop ADHD [15, 16]. Peripheral sensorimotor deficits are observed particularly in cases of spinal nerve root tumors [7]. While several clinical signs of NF1 are already present at birth, other do not develop until later in the course of the disease. In particular, the number of cutaneous neurofibromas increases with age [9].

NF1 is caused by a germline mutation in the NF1 tumor suppressor gene, which is located on the long arm of chromosome 17 (gene locus q11.2) and codes for the cytoplasmic protein
Table 1 NIH consensus criteria for diagnosis of neurofibromatosis type 1. The diagnostic criteria for NF1 are met if two or more of the following are found [4].

\begin{tabular}{l} 
criterion \\
\hline$\geq 6$ café-au-lait spots \\
- $>5 \mathrm{~mm}$ for prepubescent children \\
- $>15 \mathrm{~mm}$ for postpubertal individuals \\
\hline axillary or inguinal freckling \\
$\geq 2$ neurofibromas or $\geq 1$ plexiform neurofibroma \\
\hline 2 Lisch nodules \\
\hline defining osseous lesions \\
- sphenoid wing dysplasia \\
- dysplasia of the long bones \\
\hline optic nerve glioma \\
primary relative with NF1 per the criteria specified above
\end{tabular}

$\mathrm{NIH}$ - National Institutes of Health.

neurofibromin $[6,7]$. The protein acts to some extent as a negative regulator of the Ras-proto oncogene, a key molecule for regulating cell growth [17]. Individuals with NF1 have a higher risk of developing a plethora of benign as well as malignant tumors, with peripheral nerve sheath tumors constituting the most common entity $[4,18]$. Additional tumors associated with NF1 include, among others, optic nerve gliomas, gastrointestinal stroma tumors (GIST), rhabdomyosarcomas, pheochromocytomas and duodenal carcinoids [7, 19, 20]. Because these tumors in patients with NF1 have the same appearance with medical imaging as non-syndrome-related tumors, it is not necessary to further address such tumors in this survey article.

Neurofibromas constitute the key characteristic of NF1 and are benign schwannomas that develop in the area of the peripheral nerve sheaths and contain, in addition to neoplastic Schwann cells, fibroblasts, macrophages, mast cells and pericytes [18]. These neurofibromas are divided into four subtypes $[5,7]$ :

- Cutaneous neurofibroma: These tumors develop particularly during childhood and early adulthood, numbering several thousand per patient in extreme cases. In addition to the negative cosmetic impact, they can cause local pruritus due to the mast cells they contain [6]. No risk of transformation.

- Subcutaneous neurofibroma: Palpable subcutaneous tumors with no risk of transformation [6].

- Spinal neurofibroma: These tumors appear in individual or multiple nerve roots and are sometimes associated with sensorimotor deficits ( $\bullet$ Fig. 1) [21]. No risk of transformation.

- Diffuse or nodular plexiform neurofibroma: Plexiform neurofibromas appear in $30-50 \%$ of individuals with $\mathrm{NF} 1$, are typically present at birth and grow during adolescence [6, 7]. They expand over the length of a nerve, are rich in extracellular matrix and can exhibit infiltrative growth ( $\odot$ Fig. 2$)[22,23]$. As a result, they can cause pronounced symptoms through compression or destruction of neural structures [6, 23]. A focal malignant transformation into a malignant peripheral nerve sheath tumor can occur within a plexiform neurofibroma.

MPNST are highly malignant, aggressively metastatic tumors with an overall poor prognosis, early oncological resection being the only curative option $[18,24]$. These tu- 


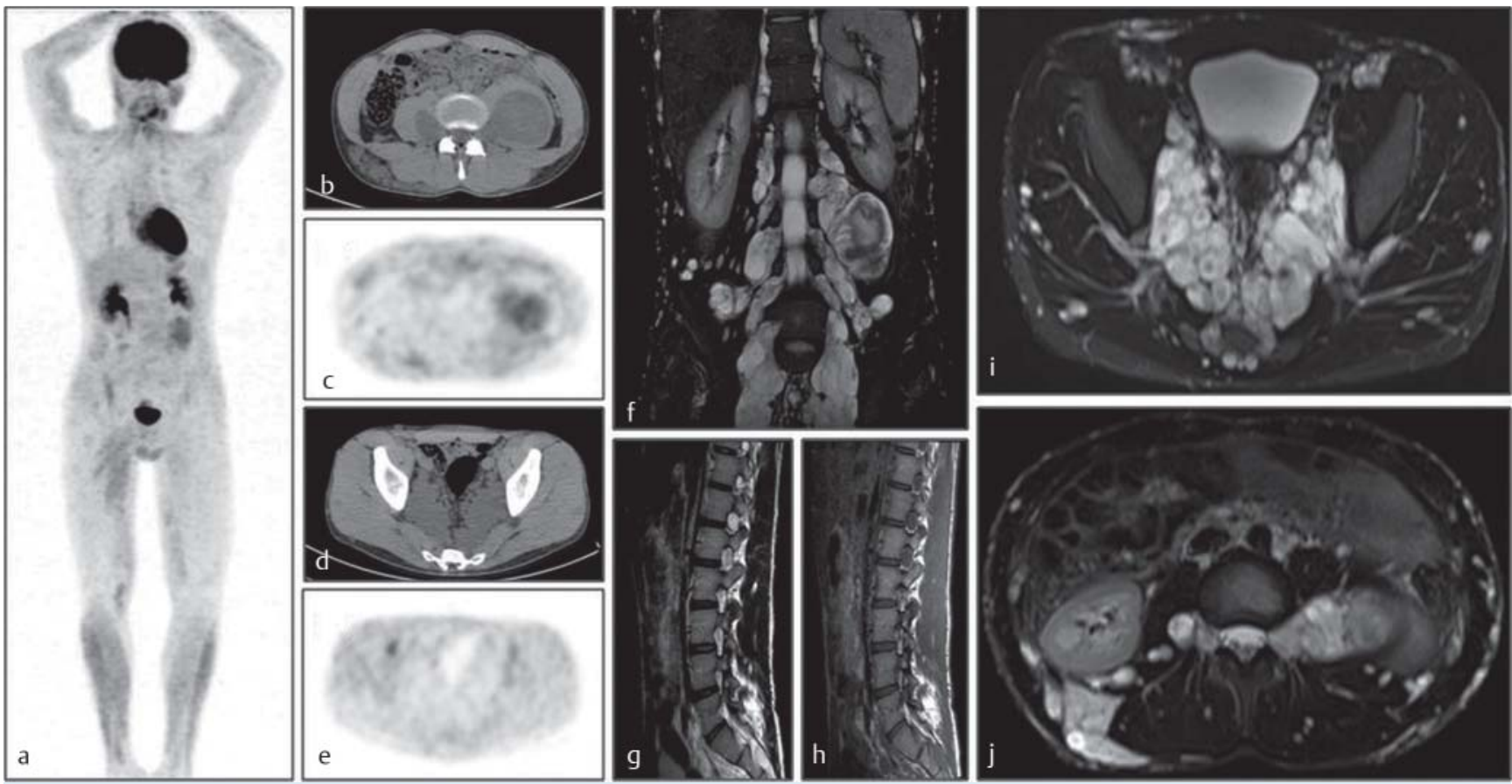

Fig. 1 20-year-old male patient with multiple spinal neurofibromas. ${ }^{18}$ F-FDG PET maximum-intensity-projection a without suspicious metabolism. Elevated glucose consumption of a neurofibroma within the left psoas muscle $\mathbf{b}$, $\mathbf{c}$. Hyperdense neurofibromas on non-enhanced CT $\mathbf{d}$ without elevated glucose metabolism e. Multiple spinal neurofibromas, hyperintense on T2w f-j.
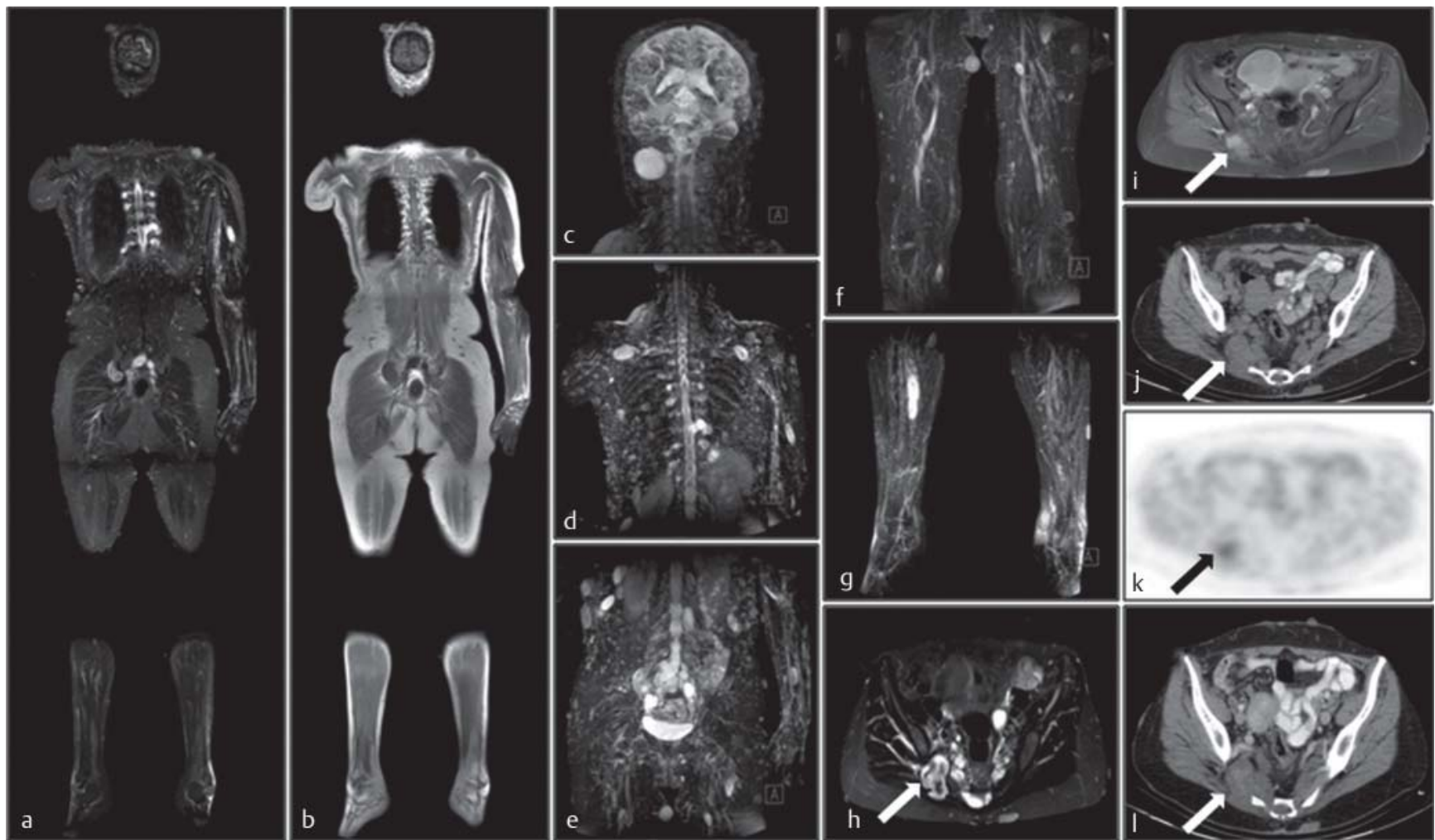

Fig. 2 31-year-old female patient with multiple subcutaneous and plexiform neurofibromas: coronal T2w a, coronal T1w b, T2w maximum-intensity-projection c-g. Axial T2w h, T1 w after contrast $\mathbf{i}$, non-enhanced CT j, PET $\mathbf{k}$ and CT after contrast I showing a large plexiform neurofibroma (arrow). 
mors form within preexisting plexiform neurofibromas [18]. Patients with NF1 have a cumulative lifetime risk of approximately $10 \%$ for developing an MPNST versus $<0.1 \%$ for the general population $[6,18,25]$. The poor prognosis also makes early detection of a malignant transformation a must.

Importance of medical imaging for neurofibromatosis type 1-associated tumors

$\nabla$

With regard to NF1-associated tumors, the key tasks of medical imaging are:

- Reliable detection of soft tissue tumors for identifying patients with plexiform neurofibromas (risk stratification) and for using as a basis for genotype-phenotype correlation studies (tumor burden), for example.

- Accurate determination of whether a tumor is benign or malignant to facilitate an early diagnosis of a possible malignant transformation. At the same time, however, reliable specific imaging characteristics must be identified to avoid unnecessary diagnostic tumor resections or biopsies with corresponding morbidity and possible mortality.

- Exact determination of the local spread of benign and malignant neurofibromas for visualizing complications, for facilitating grounded therapy planning and for therapy monitoring

\section{Role of various imaging modalities for neuro-}

fibromatosis type 1

Magnetic resonance imaging (MRI)

Whole-body MRI allows, with the aid of T2-weighted sequences, automated evaluation of whole-body tumor burden in patients with NF1 [26-28]. At the same time, whole-body MRI allows the possible presence of plexiform neurofibromas to be evaluated ( $\bullet$ Fig. 2), thereby facilitating stratification of NF1 with identification of groups at risk of developing MPNST [29, 30].

In addition, MRI can contribute to diagnosing the type of peripheral nerve sheath tumors, where a series of image features are associated with MPNST ( Tab.2) [31-33]. However, these characteristics are not present in all MPNST and in some cases clearly overlap with those of benign PNST. Unlike the metabolic activity in ${ }^{18} \mathrm{~F}-\mathrm{FDG}$ PET ( $\odot$ Tab.3) no singular criterion for reliable differentiation and deciding in favor of or against a performing a biopsy have been found for MRI. Thus the presence of two or more malignancy criteria described as significant is postulated to indicate performing a biopsy.[32]. In addition, criteria described in individual articles as being significantly associated with MPNST have not been reproducible in all studies. In some cases, characteristics ascribed to MPNST such as, for example, an irregular tumor shape were associated more with benign tumors in several studies [31, 35]. A characteristic criterion of peripheral nerve sheath tumors is the presence of what is referred to as target sign ( $\bullet$ Fig. 3 ), which is frequently present particularly in the case of subcutaneous neurofibroma. This is characterized by a central hypointense area in an overall homogenous hyperintense spaceoccupying lesion in $\mathrm{T} 2 \mathrm{w}$, and is attributed to a central accumulation of dense collagen-rich stroma [31]. In rare cases, however, this can also be observed with MPNST [33], e.g. when there is a central malignant transformation.

A characteristic criterion of MPNST is a significantly larger tumor size compared to benign PNST. Demehri et al. measured a tumor size of $68 \pm 18 \mathrm{~mm}$ for MPNST and $39 \pm 23$ for benign PNST. Other research groups yielded similar results, with an a priori threshold value of $5 \mathrm{~cm}$ frequently being used ( Tab.2) [31-33, 35]. This is explained by the fact that MPNST form within existing plexiform neurofi-

Tab. 2 Selected publications on diagnostic criteria for determining whether peripheral nerve sheath tumors in NF1 are benign or malignant using MRI [31 - 33, 35].

\begin{tabular}{|c|c|c|c|c|c|c|c|c|c|c|c|c|}
\hline \multirow[t]{2}{*}{ Parameter } & \multicolumn{3}{|c|}{ Matsumine et al. [31] } & \multicolumn{3}{|c|}{ Wasa et al. [32] } & \multicolumn{3}{|c|}{ Derlin et al. [33] } & \multicolumn{3}{|c|}{ Demehri et al. [35] } \\
\hline & MPNST & BPNST & $p$ & MPNST & BPNST & $p$ & MPNST & BPNST & $p$ & MPNST & BPNST & $p$ \\
\hline tumor size (mm) & $94^{1}$ & $69^{1}$ & 0.07 & 100 & 50 & 0.029 & $74 \pm 45$ & $43 \pm 48$ & $<0.005$ & $63 \pm 18$ & $39 \pm 23$ & 0.009 \\
\hline irregular tumor size & $79 \%$ & $28 \%$ & 0.02 & $\mathrm{n} / \mathrm{a}$ & $\mathrm{n} / \mathrm{a}$ & $\mathrm{n} / \mathrm{a}$ & $\mathrm{n} / \mathrm{a}$ & $\mathrm{n} / \mathrm{a}$ & $\mathrm{n} / \mathrm{a}$ & $0 \%$ & $13 \%$ & 0.53 \\
\hline unclear margins & $68 \%$ & $33 \%$ & 0.03 & $\mathrm{n} / \mathrm{a}$ & $\mathrm{n} / \mathrm{a}$ & $\mathrm{n} / \mathrm{a}$ & $38 \%$ & $3 \%$ & 0.007 & $77 \%$ & $32 \%$ & 0.04 \\
\hline intratumoral lobulation & $63 \%$ & $17 \%$ & 0.007 & $\mathrm{n} / \mathrm{a}$ & $\mathrm{n} / \mathrm{a}$ & $\mathrm{n} / \mathrm{a}$ & $50 \%$ & $12 \%$ & $<0.02$ & $\mathrm{n} / \mathrm{a}$ & $\mathrm{n} / \mathrm{a}$ & $\mathrm{n} / \mathrm{a}$ \\
\hline intratumoral heterogeneity ( $\mathrm{T} 1 \mathrm{w})$ & $90 \%$ & $50 \%$ & 0.01 & $51 \%$ & $30 \%$ & 0.117 & $88 \%$ & $52 \%$ & 0.07 & $0 \%$ & $4 \%$ & 0.49 \\
\hline $\begin{array}{l}\text { irregular or peripheral } \\
\text { contrast enhancement }\end{array}$ & $74 \%$ & $33 \%$ & 0.05 & $34 \%$ & $5 \%$ & 0.006 & $75 \%$ & $15 \%$ & $<0.001$ & $\mathrm{n} / \mathrm{a}$ & $\mathrm{n} / \mathrm{a}$ & $\mathrm{n} / \mathrm{a}$ \\
\hline intratumoral cystic changes & $21 \%$ & $17 \%$ & 1 & 39 & $10 \%$ & 0.02 & $0 \%$ & 0 & 1 & $\mathrm{n} / \mathrm{a}$ & $\mathrm{n} / \mathrm{a}$ & $\mathrm{n} / \mathrm{a}$ \\
\hline peritumoral edema & $\mathrm{n} / \mathrm{a}$ & $\mathrm{n} / \mathrm{a}$ & $\mathrm{n} / \mathrm{a}$ & $29 \%$ & $0 \%$ & 0.005 & $\mathrm{n} / \mathrm{a}$ & $\mathrm{n} / \mathrm{a}$ & $\mathrm{n} / \mathrm{a}$ & $66 \%$ & $23 \%$ & 0.01 \\
\hline target sign & $0 \%$ & $67 \%$ & $<0.0001$ & $\mathrm{n} / \mathrm{a}$ & $\mathrm{n} / \mathrm{a}$ & $\mathrm{n} / \mathrm{a}$ & $25 \%$ & $57 \%$ & 0.14 & $\mathrm{n} / \mathrm{a}$ & $\mathrm{n} / \mathrm{a}$ & $\mathrm{n} / \mathrm{a}$ \\
\hline
\end{tabular}

MPNST - malignant peripheral nerve sheath tumors; BPNST - benign peripheral nerve sheath tumor; CE - contrast enhanced; 1 median
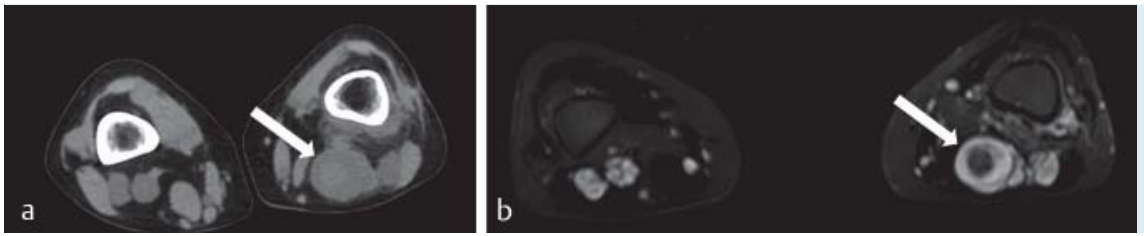

Fig. 3 11-year-old female patient with subcutaneous neurofibromas. Target sign: large subcutaneous neurofibroma (arrow) showing central hyperdense area on non-enhanced CT a and corresponding hypointense area on $\mathrm{T} 2 \mathrm{w} \mathbf{b}$. 
broma, thus resulting in an addition of existing benign tumor mass and malignant tissue portions. Furthermore, this is primarily a result, however, of the often late diagnosis. Poorly defined demarcation with surrounding tissue is another malignancy criterion $[31,33,35]$. However, this is likewise a relatively advanced sign of a malignant transformation, since in this case growth exceeding the capsule must be present, which - given the genesis of MPNST from plexiform neurofibromas - can be expected to appear late. An intratumoral lobulation in T1w can be observed in many MPNST, but also for $12-17 \%$ of plexiform neurofibromas $[31,33]$. The lobulation apparently is rooted in the reticulated growth of the plexiform neurofibromas, which can involve multiple nerve fascicles and lead to a diffuse accumulation of densified nerves [22]. Another characteristic of MPNST is presentation of portions appearing hyperintense in $\mathrm{T} 1 \mathrm{w}$, which lead to an overall inhomogenous appearance of MPNST in T1w [31]. Histologically, this corresponds to intratumoral hemorrhagic areas [31]. An irregular contrast medium enhancement in T1w reflects the presence of various perfused tissue portions within a spaceoccupying lesion, suggests the presence of malignant tumor portions and is significantly associated with MPNST [31]. However, irregular contrast medium en- hancement appears also with plexiform neurofibromas [31-33], which constitute histologically heterogeneous tumors. Constituting another malignancy criterion, peritumoral edema is present in $29-66 \%$ of cases of MPNST, yet can also be present with benign nerve sheath tumors [32, 35]. Intratumoral cystic changes in T2w as signs of, e. g., cystically degenerated infarctions with large neurofibromas were likewise associated with MPNST [32]. However, this finding was not reproduced in other studies [31, 33].

In addition to anatomical MRI sequences, quantitative MRI imaging techniques such as diffusion-weighted imaging (DWI) and dynamic contrast-enhanced MRI (DCE-MRI) can be used for characterizing nerve sheath tumors ( $\bullet$ Fig.4). DCE-MRI constitutes a quantitative method for evaluating tumor profusion, for which significantly different imaging patterns have been described particularly when it comes to differentiating benign and malignant soft tissue tumors [34]. In a current article, Demehri et al. observed that when DCE-MRI was used to examine 9 MPNST and 22 nerve sheath tumors, $50 \%$ of the MPNST exhibited an early arterial contrast medium enhancement, which, however, was discovered in only $11 \%$ of the benign peripheral nerve sheath tumors [35].
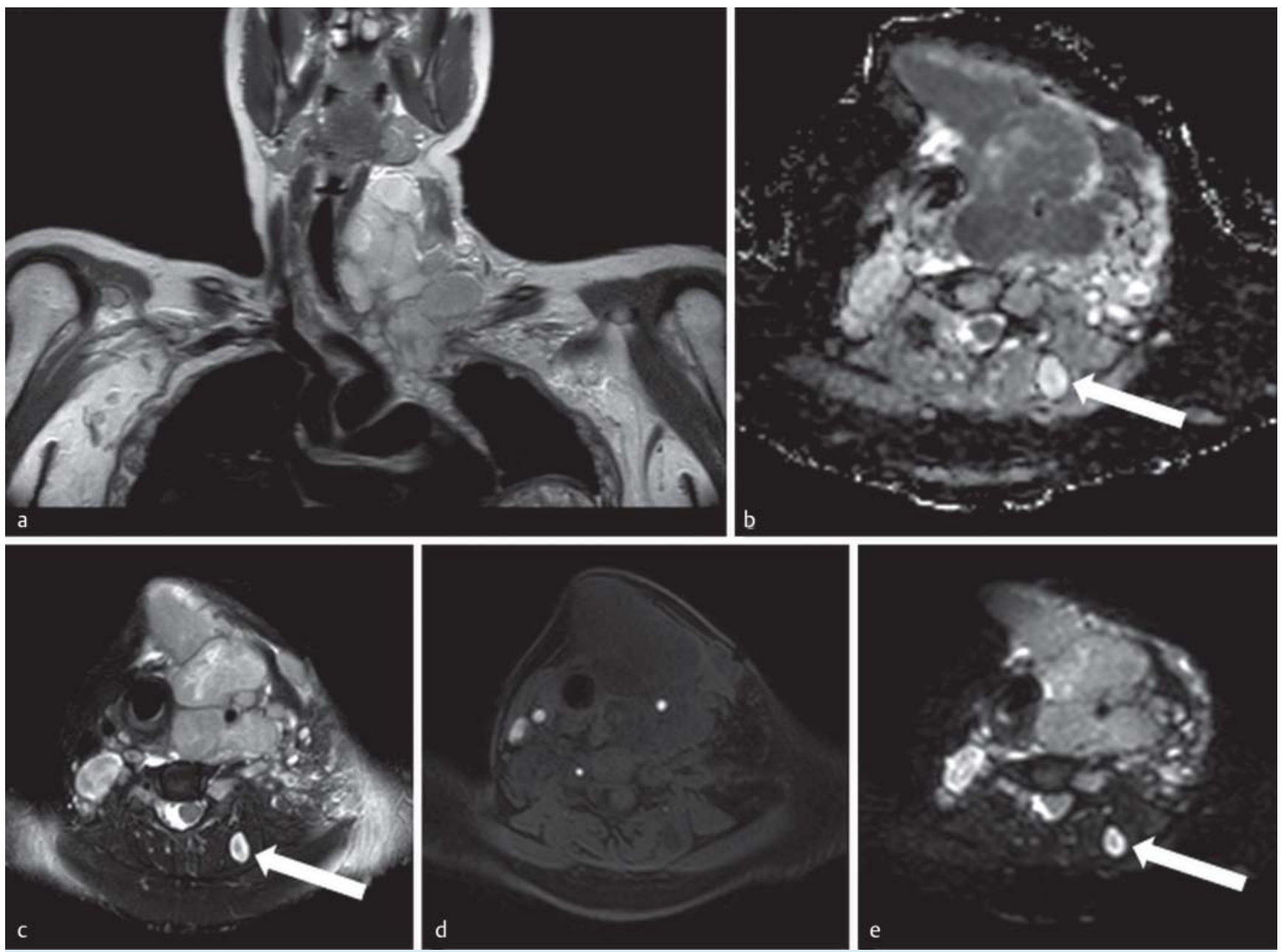

Fig. 4 35-year-old female patient with MPNST. Large lobulated head-and-neck tumor on coronal T1w a with restricted diffusion in the ADC map b, inhomogeneous signal on T2w and T1w with fat suppression $\mathbf{c}, \mathbf{d}$ and signal reduction on DWI (b 100) e compared to the neurofibroma in the left M. erector spinae with target sign (arrow) $\mathbf{c}$ and higher ADC-value b. 

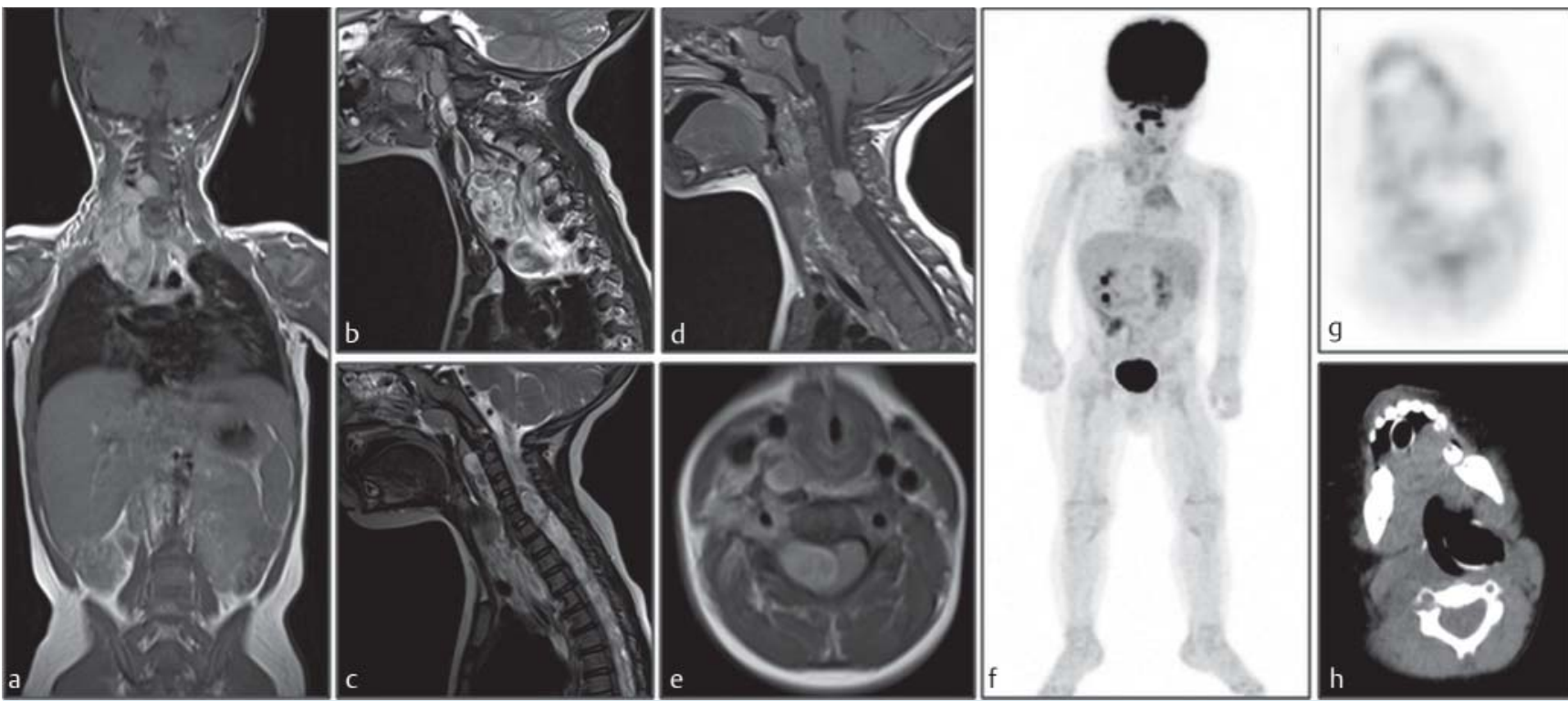

Fig. 5 2-year-old female patient with plexiform neurofibroma. Large lobulated head-and-neck tumor on coronal T1w a with inhomogeneous signal on T2w b and intraspinal growth (T1w and T2w, c-e). ${ }^{18}$ F-FDG PET maximum-intensity-projection $\mathbf{f}$ without suspicious metabolism as seen on transversal $\mathrm{PET} \mathbf{g}$; corresponding non-enhanced $\mathrm{CT} \mathbf{h}$.

To put it simply, diffusion-weighted imaging is based on the limited diffusion (random thermal motion of water molecules) owing to the high cell density in tumors [36]. For characterizing soft tissue lesions, the anatomical localization and observation of ADC values - in addition to the signal intensity in DWI - are critical [36]. In a study involving 31 histologically confirmed nerve sheath tumors, the minimal, yet not the median, ADC values were significantly lower in MPNST than in benign nerve sheath tumors. While a sensitivity of $100 \%$ and a specificity of $77 \%$ MPNST were identified at a minimum ADC value of $<1.0 \times 10^{-3} \mathrm{~mm}^{2} / \mathrm{s}$, even this limited specificity was observed only in tumors with a diameter of $\geq 4.2 \mathrm{~cm}$. An even lower specificity must be assumed for smaller lesions [35]. In another study involving 29 patients, MPNST exhibited in diffusion tensor imaging (DTI) a significantly lower diffusivity than benign tumors $\left(0.900 \pm 0.25\right.$ versus $1.848 \pm 0.40 \times 10^{-3} \mathrm{~mm}^{2} / \mathrm{s}$; $p<0.001$ ), with this difference not being significant for ADC values from DWI sequences [37]. Even though quantitative MRI parameters may possibly contribute to diagnosing nerve sheath tumors, the existing data is relatively limited, preventing the exact clinical value of these methods with regard to NF1-associated tumors from being definitively evaluated at this time.

Although the diagnostic differentiation of peripheral nerve sheath tumors in MRI can be complex in a single examination, serial MRI facilitates the detection of changes in the appearance of plexiform neurofibromas, which are then highly suggestive of malignant transformation [29]. Owing to its high soft tissue contrast, MRI provides superior detection of the extent of malignant and plexiform nerve sheath tumors as well as evaluation of the neighboring structures ( $\bullet$ Fig.5), which is often indispensable for both planning possible surgical therapy and for precise follow-up, in the latter case also because of the absence of radiation exposure among a generally rather young patient population.
Table 3 Recommended SUV ${ }_{\text {max }}$-thresholds for assessing whether peripheral nerve sheath tumors in NF1 are benign or malignant $[26,27]$

\begin{tabular}{|c|c|c|}
\hline $\begin{array}{l}\text { SUV }_{\text {max }} \\
\text { threshold }\end{array}$ & interpretation & consequence \\
\hline$<2.5$ & probably benign & - \\
\hline $2.5-3.5$ & needs to be tested & follow-up examination \\
\hline$>3.5$ & probably malignant & biopsy \\
\hline
\end{tabular}

\section{Positron emission tomography / computed tomography (PET/CT)}

As a combined metabolic-anatomic method, combined positron emissions tomography / computed tomography (PET/ CT) using the radiotracer ${ }^{18} \mathrm{~F}$-Fluorodeoxyglucose (FDG) allows multiple relevant parameters of nerve sheath tumors to be recorded simultaneously. Because of the elevated glucose metabolism, MPNST ( $\bullet$ Fig. 6 ) can be detected with both high sensitivity and specificity [38]. At the same time, ${ }^{18}$ F-FDG PET/CT permits high-sensitivity whole-body staging in cases of MPNST. Simultaneous CT is highly valuable particularly in cases with typical osseous and pulmonary metastasis locations. For detecting MPNST, threshold values for SUV $_{\max }$ are normally used ( $\bullet$ Tab.3), with each nerve sheath tumor having an $\mathrm{SUV}_{\max } \geq 3.5$ generally being viewed as potentially malignant $[38,39]$. According to the study consulted, the optimal SUV $\mathrm{Sux}_{\max }$ varies also depending on the different acquisition protocols between 3.1 and 6.1, with specificities between 77 and 95\% being achieved [38-42]. In NF1 patients, an unremarkable PET/CET excludes a malignant transformation with high likelihood, the negative predictive value of ${ }^{18} \mathrm{~F}$-FDG PET/CT being as high as $100 \%$ in newer studies [39]. In addition, the metabolic activity $\left(\mathrm{SUV}_{\max }\right)$ is a better predictor for overall survival than histological grading [43].

The specificity and thus the positive predictive value of ${ }^{18} \mathrm{~F}-\mathrm{FDG} \mathrm{PET} / \mathrm{CT}$ is, however, not completely satisfactory for 


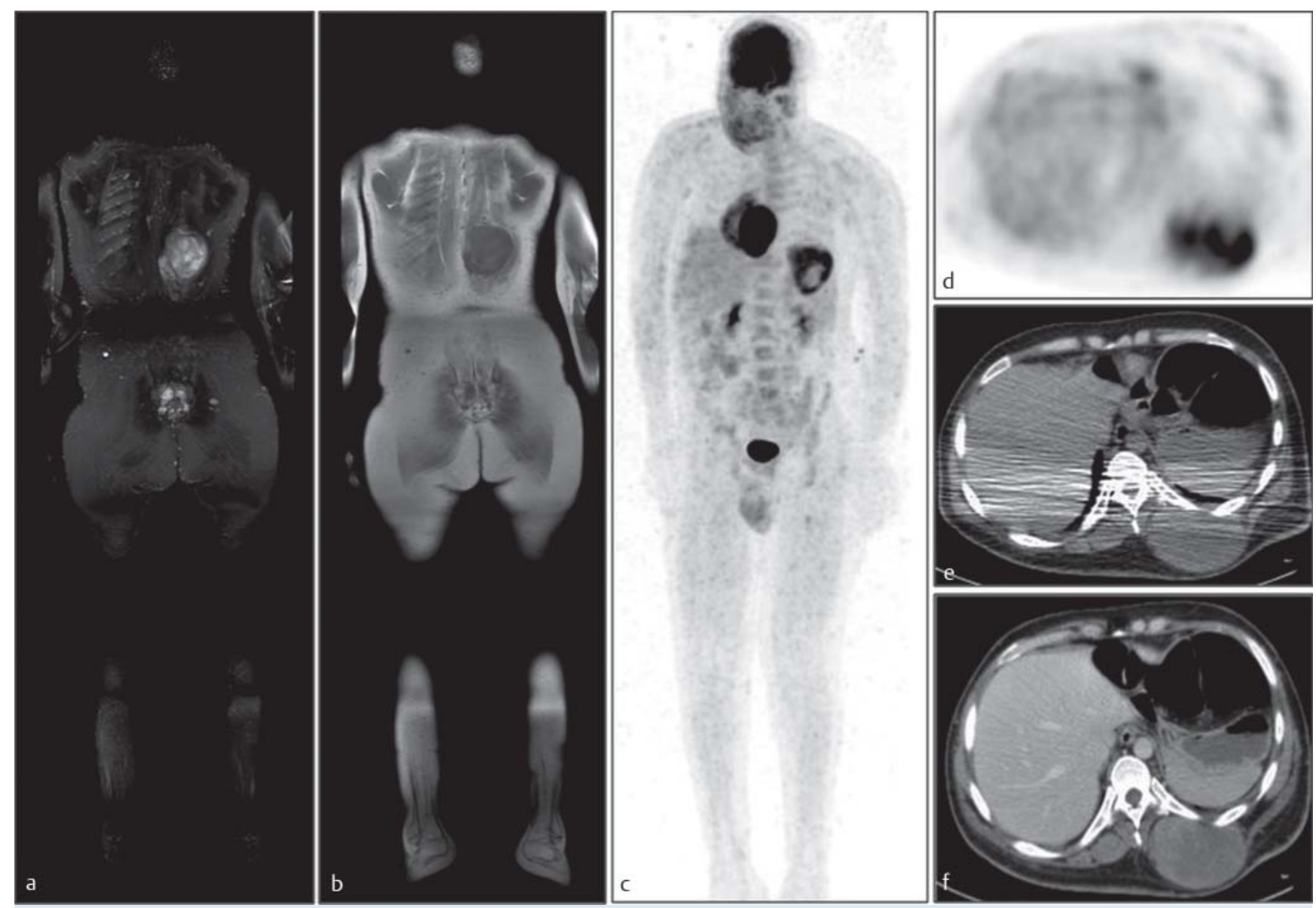

Fig. 6 27-year-old patient with MPNST. Coronal T2w a, coronal T1w b, 18F-FDG PET maximum-intensity-projection c, transversal PET d, transversal nonenhanced $\mathrm{CT}$ e and transversal $\mathrm{CT}$ after contrast $\mathbf{f}$ showing a inhomogeneous tumor with elevated metabolism.

the detection of MPNST. This is due to the fact that in a portion of cases, plexiform neurofibroma can exhibit relevant glucose metabolism $[38,41]$. In addition, other tumors associated with NF1 - such as phaeochromocytoma or ganglioneuroma - exhibit in some cases pronounced glucose utilization $[39,44]$ and should thus be taken into consideration during differential diagnosis when they are found at the appropriate location. Cutaneous, subcutaneous and spinal neurofibroma show no relevant uptake of ${ }^{18} \mathrm{~F}$-FDG. To improve the specificity of ${ }^{18} \mathrm{~F}$-FDG PET/CT, modified acquisition protocols with the addition of delayed imaging and normalization of tumor metabolism on a reference tissue are used in addition to standard imaging techniques (๑ Tab.4) [38, 45-47]. For malignant tumors, it is postulated that tracer uptake increase over time [38]. With regard to the increased specificity resulting from delayed imaging, some studies showed positive results [38], while others showed no significant difference [47]. Normalizing tumor metabolism to a reference tissue should allow the balancing out of interindividual differences in physiological and physical factors which could influence an absolutely comparative SUV quantification, such as difference in blood sugar level or the time of acquisition following tracer injection [46]. According to a current article, it was thus possible to increase specificity from $80 \%$ to $90 \%$ by using a tumor-toliver ratio with a threshold value of $>2.6$ [45]. In another study by Chirindel et al., normalizing tracer uptake to liver activity allowed the specificity of the early imaging to be increased from $87 \%$ to $94 \%$ at high sensitivity, while the delayed imaging provided no significant increase in specificity over that of the early imaging. [47].

Even if other PET radiopharmaceuticals such as the proliferation marker F-18 fluorothymidine (FLT) are available in principle for in vivo characterization of peripheral nerve sheath tumors and could measure potentially more specific parameters of a malignant transformation, there are currently no larger-scale studies in this regard involving patients with NF1.

\section{Computed tomography (CT)}

The role of CT in differentiating peripheral nerve sheath tumors is primarily the subject of older studies involving smaller patient populations $[48,49]$. Neurofibromas can exhibit low density on CT. This is due to the presence of lipidrich Schwann cells, transformed adipocytes, accumulation of interstitial fluid and cystic areas resulting from infarctions and necrosis, particularly in cases of larger and malignant nerve sheath tumors [48]. In addition, perineural fat tissue can be entrapped particularly with the growth of diffuse plexiform neurofibromas, thereby causing lower density values on CT [48]. In our experience, intratumoral density differences in computed tomograms are often already discernable without contrast medium ( $\bullet$ Fig. 3 ). After contrast medium is administered, many peripheral nerve 
Table 4 Selected publications on diagnostic accuracy of ${ }^{18} \mathrm{~F}-\mathrm{FDG}$ PET and PET/CT for assessing whether peripheral nerve sheath tumors in patients with NF1 are malignant or benign [38-41, $45-47]$.

\begin{tabular}{|c|c|c|c|c|c|c|c|c|c|}
\hline \multirow[t]{2}{*}{ authors } & \multirow[t]{2}{*}{$\begin{array}{l}\text { number of } \\
\text { patients }\end{array}$} & \multirow{2}{*}{$\begin{array}{l}\text { number of } \\
\text { lesions } \\
\text { (MPNST) }\end{array}$} & \multirow[t]{2}{*}{$\begin{array}{l}\text { time of } \\
\text { imaging }\end{array}$} & \multirow[t]{2}{*}{$\begin{array}{l}\text { Quantified } \\
\text { parameter }\end{array}$} & \multirow[t]{2}{*}{ threshold value } & \multicolumn{2}{|c|}{$\begin{array}{l}\text { median glucose } \\
\text { utilization }\end{array}$} & \multirow[t]{2}{*}{ sensitivity } & \multirow[t]{2}{*}{ specificity } \\
\hline & & & & & & MPNST & benigne NF & & \\
\hline \multirow[t]{2}{*}{ Warbey et al. [38] } & 69 & $85(21)$ & 1,5 h p. i. & SUV $_{\max }$ & $>2.4$ & $\mathrm{n} / \mathrm{a}$ & $\mathrm{n} / \mathrm{a}$ & $100 \%$ & $60 \%$ \\
\hline & & & 4 h p.i. & $S U V_{\max }$ & $>3.1$ & $\mathrm{n} / \mathrm{a}$ & $\mathrm{n} / \mathrm{a}$ & $100 \%$ & $77 \%$ \\
\hline Salamon et al. [39] & 50 & $164(19)$ & 1 h p.i. & SUV $_{\max }$ & $\geq 3.5$ & $8.4 \pm 3.2$ & $2.6 \pm 1.2$ & $100 \%$ & $79 \%$ \\
\hline Ferner et al. [40] & 105 & $116(29)$ & $1+4$ h p. i. & $\mathrm{SUV}_{\max }$ & $\begin{array}{l}>\text { Liver + no } \\
\text { drop after } 4 \mathrm{~h}\end{array}$ & $5.7 \pm 2.6$ & $1.5 \pm 1.1$ & $89 \%$ & $95 \%$ \\
\hline Benz et al. [41] & 34 & $40(17)$ & 1 h p.i. & $\mathrm{SUV}_{\max }$ & $\geq 6.1$ & $12.8 \pm 8.6$ & $2.3 \pm 0.7$ & $94 \%$ & $91 \%$ \\
\hline Salamon et al. [45] & 49 & $152(18)$ & 1 h p.i. & $\begin{array}{l}\text { Tumor-liver- } \\
\text { ratio }\end{array}$ & $>2.6$ & $\mathrm{n} / \mathrm{a}$ & $\mathrm{n} / \mathrm{a}$ & $100 \%$ & $90 \%$ \\
\hline $\begin{array}{l}\text { Combemale et al. } \\
\text { [46] }\end{array}$ & 113 & $145(40)$ & 1 h p.i. & $\begin{array}{l}\text { Tumor-liver- } \\
\text { ratio }\end{array}$ & $>1.5$ & $\mathrm{n} / \mathrm{a}$ & $\mathrm{n} / \mathrm{a}$ & $97 \%$ & $76 \%$ \\
\hline \multirow[t]{4}{*}{ Chirindel et al. [47] } & 41 & $93(24)$ & 1 h p.i. & $S U L_{\max }$ & $>3.2$ & $6.5 \pm 2.9$ & $2.0 \pm 0.9$ & $92 \%$ & $87 \%$ \\
\hline & & & 4 h p.i. & $\mathrm{SUL}_{\max }$ & $>4.1$ & $8.3 \pm 3.8$ & $2.3 \pm 1.2$ & $96 \%$ & $88 \%$ \\
\hline & & & 1 h p.i. & $\begin{array}{l}\text { Tumor-liver- } \\
\text { ratio }\end{array}$ & $>2.7$ & $\mathrm{n} / \mathrm{a}$ & $\mathrm{n} / \mathrm{a}$ & $92 \%$ & $94 \%$ \\
\hline & & & 4 h p.i. & $\begin{array}{l}\text { Tumor-liver- } \\
\text { ratio }\end{array}$ & $>4.3$ & $\mathrm{n} / \mathrm{a}$ & $\mathrm{n} / \mathrm{a}$ & $96 \%$ & $93 \%$ \\
\hline
\end{tabular}

sheath tumors exhibit an inhomogenous contrast enhancement, which is due not only to cystic areas, but also to regions of differing cellularity and collagen density [49]. The contrast enhancement and the inhomogeneous nature thereof do not allow reliable differentiation of benign plexiform and malignant tumors $[49,50]$.

Contrast-enhanced CT is widely used for NF1 in the process of tumor staging, particularly in conjunction with ${ }^{18} \mathrm{~F}-\mathrm{FDG}$ PET/CT. Today, other use of contrast-enhanced CT is reserved essentially for special situations such as the further clarification of unclear findings gathered from MRI or PET (e.g., the exact location of the tumor in relation to blood vessels in cases of complex tumor locations) or for the imaging of subcranial tumors.

\section{Conclusions}

Whole-body MRI is the current reference standard for detecting soft tissue tumors in cases of NF1 and permits not only the reliable identification of individuals with plexiform neurofibromas, but also precise assessment of local tumor extent and evaluation of whole-body tumor burden. Multiparametric MRI can additionally provide a comprehensive characterization of peripheral nerve sheath tumors. It also allows parameters suggestive of MPNST to be detected with sensitivity. Because it involves no radiation exposure, whole-body MRI is suited for serial follow-up in patients with plexiform neurofibromas. ${ }^{18} \mathrm{~F}-\mathrm{FDG}$-PET/CT allows highly sensitive and specific detection of MPNST in individuals with NF1 and should be used when a malignant transformation of a nerve sheath tumor is suspected, particularly for staging. Today, the use of contrast-enhanced CT in diagnosing peripheral nerve sheath tumors is still limited to special indications. Combined PET/MRI can unite the advantages of ${ }^{18} \mathrm{~F}$-FDG PET/CT and appears to be a highly promising method for evaluating nerve sheath tumors in NF1 patients. To optimally diagnose individuals with NF1, specialized examination protocols should be employed, and radiologists and nuclear medicine physicians should be familiar with the complex and variable morphology of peripheral nerve sheath tumors.

\section{References}

1 Lammert M, Friedman JM, Kluwe L et al. Prevalence of neurofibromatosis 1 in German children at elementary school enrollment. Arch Dermatol 2005; 141: 71 - 74

2 Huson SM, Harper PS, Compston DA. Von Recklinghausen neurofibromatosis: a clinical and population study in south-east Wales. Brain 1988; 111: $1355-1381$

3 Reynolds RM, Browning GG, Nawroz I et al. Von Recklinghausen's neurofibromatosis: neurofibromatosis type 1 . Lancet 2003; 361: 1552 1554

4 National Institutes of Health Consensus Development Conference Statement: neurofibromatosis. Bethesda, Md., USA, July 13-15, 1987. Neurofibromatosis 1988; 1: $172-178$

5 Ferner RE, Huson SM, Thomas $N$ et al. Guidelines for the diagnosis and management of individuals with Neurofibromatosis 1 (NF1). J Med Genet 2007; 44: $81-88$

6 Williams VC, Lucas J, Babcock MA et al. Neurofibromatosis type 1 revisited. Pediatrics 2009; 123: 124-133

7 Hirbe AC, Gutmann DH. Neurofibromatosis type 1: a multidisciplinary approach to care. Lancet Neurol 2014; 13: $834-843$

8 De Schepper S, Boucneau J, Vander Haeghen Y et al. Café-au-lait spots in neurofibromatosis type 1 and in healthy control individuals: hyperpigmentation of a different kind? Arch Dermatol Res 2006; 297: $439-449$

9 Duong TA, Bastuji-Garin S, Valeyrie-Allanore L et al. Evolving pattern with age of cutaneous signs in neurofibromatosis type 1: a cross-sectional study of 728 patients. Dermatology 2011; 222: 269-273

10 Boley S, Sloan JL, Pemov A et al. A quantitative assessment of the burden and distribution of Lisch nodules in adults with neurofibromatosis type 1. Invest Ophthalmol Vis Sci 2009; 50: 5035-5043

11 Jaremko JL, MacMahon PJ, Torriani M et al. Whole-body MRI in neurofibromatosis: incidental findings and prevalence of scoliosis. Skeletal Radiol 2012; 41: 917 - 923

12 Elefteriou F, Kolanczyk M, Schindeler A et al. Skeletal abnormalities in neurofibromatosis type 1: approaches to therapeutic options. Am J Med Genet A 2009; 149A: 2327-2338

13 Friedman JM, Arbiser J, Epstein JA et al. Cardiovascular disease in neurofibromatosis 1: report of the NF1 Cardiovascular Task Force. Genet Med 2002; 4: 105-111

14 Nguyen R, Mir TS, Kluwe L et al. Cardiac characterization of 16 patients with large NF1 gene deletions. Clin Genet 2013; 84: 344-349 
15 Ferner RE, Hughes RA, Hall SM et al. Neurofibromatous neuropathy in neurofibromatosis 1 (NF1). J Med Genet 2004; 41: 837-841

16 Lehtonen A, Howie E, Trump D et al. Behaviour in children with neurofibromatosis type 1: cognition, executive function, attention, emotion, and social competence. Dev Med Child Neurol 2013; 55: 111 - 125

17 Gutmann DH, Parada LF, Silva AJ et al. Neurofibromatosis type 1: modeling CNS dysfunction. J Neurosci 2012; 32: 14087-14093

18 Ducatman BS, Scheithauer BW, Piepgras DG et al. Malignant peripheral nerve sheath tumors: a clinicopathologic study of 120 cases. Cancer 1986; 57: 2006-2021

19 Brems H, Beert E, de Ravel T et al. Mechanisms in the pathogenesis of malignant tumours in neurofibromatosis type 1. Lancet Oncol 2009; 10: $508-515$

20 Laycock-van Spyk S, Thomas N, Cooper DN et al. Neurofibromatosis type 1-associated tumours: their somatic mutational spectrum and pathogenesis. Hum Genomics 2011; 5: 623-690

21 Poyhonen M, Leisti EL, Kytola S et al. Hereditary spinal neurofibromatosis: a rare form of NF1? J Med Genet 1997; 34: 184-187

22 Korf BR. Plexiform neurofibromas. Am J Med Genet 1999; 89: 31 - 37

23 Mautner VF, Hartmann M, Kluwe L et al. MRI growth patterns of plexiform neurofibromas in patients with neurofibromatosis type 1 . Neuroradiology 2006; 48: 160 - 165

24 Ferner RE, Gutmann DH. International consensus statement on malignant peripheral nerve sheath tumors in neurofibromatosis. Cancer Res 2002; 62: $1573-1577$

25 Evans DG, Baser ME, McGaughran J et al. Malignant peripheral nerve sheath tumours in neurofibromatosis 1. J Med Genet 2002; 39: 311 314

26 Cai W, Kassarjian A, Bredella MA et al. Tumor burden in patients with neurofibromatosis types 1 and 2 and schwannomatosis: determination on whole-body MR images. Radiology 2009; 250: 665 - 673

27 Plotkin SR, Bredella MA, Cai W et al. Quantitative assessment of wholebody tumor burden in adult patients with neurofibromatosis. PLoS One 2012; 7: e35711

28 Kluwe L, Nguyen R, Vogt J et al. Internal tumor burden in neurofibromatosis Type I patients with large NF1 deletions. Genes Chromosomes Cancer 2012; 51: 447-451

29 Tucker T, Friedman JM, Friedrich RE et al. Longitudinal study of neurofibromatosis 1 associated plexiform neurofibromas. J Med Genet 2009; 46: $81-85$

30 Nguyen R, Jett $K$, Harris GJ et al. Benign whole body tumor volume is a risk factor for malignant peripheral nerve sheath tumors in neurofibromatosis type 1. J Neurooncol 2014; 116: 307 - 313

31 Matsumine A, Kusuzaki K, Nakamura T et al. Differentiation between neurofibromas and malignant peripheral nerve sheath tumors in neurofibromatosis 1 evaluated by MRI. J Cancer Res Clin Oncol 2009; 135 : $891-900$

32 Wasa J, Nishida Y, Tsukushi S et al. MRI features in the differentiation of malignant peripheral nerve sheath tumors and neurofibromas. Am J Roentgenol 2010; 194: 1568-1574

33 Derlin T, Tornquist K, Münster S et al. Comparative effectiveness of $18 \mathrm{~F}-$ FDG PET/CT versus whole-body MRI for detection of malignant peripheral nerve sheath tumors in neurofibromatosis type 1. Clin Nucl Med 2013; 38: e19-e25

34 van Rijswijk CS, Geirnaerdt MJ, Hogendoorn PC et al. Soft-tissue tumors: value of static and dynamic gadopentetate dimeglumine-enhanced
MR imaging in prediction of malignancy. Radiology 2004; 233: $493-$ 502

35 Demehri S, Belzberg A, Blakeley J et al. Conventional and functional MR imaging of peripheral nerve sheath tumors: initial experience. AJNR Am J Neuroradiol 2014; 35: 1615-1620

36 Wilhelm T, Stieltjes B, Schlemmer HP. Whole-Body-MR-Diffusion Weighted Imaging in Oncology. Fortschr Röntgenstr 2013; 185: 950 958

37 Chhabra A, Thakkar RS, Andreisek $G$ et al. Anatomic MR imaging and functional diffusion tensor imaging of peripheral nerve tumors and tumorlike conditions. AJNR Am J Neuroradiol 2013; 34: 802 - 807

38 Warbey VS, Ferner RE, Dunn JT et al. [18F]FDG PET/CT in the diagnosis of malignant peripheral nerve sheath tumours in neurofibromatosis type-1. Eur J Nucl Med Mol Imaging 2009; 36: 751 - 757

39 Salamon J, Derlin T, Bannas P et al. Evaluation of intratumoural heterogeneity on ${ }^{18} \mathrm{~F}-\mathrm{FDG}$ PET/CT for characterization of peripheral nerve sheath tumours in neurofibromatosis type 1. Eur J Nucl Med Mol Imaging 2013; 40: 685-692

40 Ferner RE, Golding JF, Smith M et al. [18F]2-fluoro-2-deoxy-D-glucose positron emission tomography (FDG PET) as a diagnostic tool for neurofibromatosis 1 (NF1) associated malignant peripheral nerve sheath tumours (MPNSTs): a long-term clinical study. Ann Oncol 2008; 19: $390-394$

41 Benz MR, Czernin J, Dry SM et al. Quantitative F18-fluorodeoxyglucose positron emission tomography accurately characterizes peripheral nerve sheath tumors as malignant or benign. Cancer 2010; 116: 451 458

42 Moharir M, London K, Howman-Giles R et al. Utility of positron emission tomography for tumour surveillance in children with neurofibromatosis type 1. Eur J Nucl Med Mol Imaging 2010; 37: 1309-1317

43 Brenner W, Friedrich RE, Gawad KA et al. Prognostic relevance of FDG PET in patients with neurofibromatosis type- 1 and malignant peripheral nerve sheath tumours. Eur J Nucl Med Mol Imaging 2006; 33: $428-432$

44 Derlin T, Hagel C, Mautner VF. Syndromic abdominal ganglioneuroma: a rare cause of false-positive findings in the F-18 FDG PET / CT in neurofibromatosis type 1. Fortschr Röntgenstr 2014; 186: 706-707

45 Salamon J, Veldhoen S, Apostolova I et al. 18F-FDG PET/CT for detection of malignant peripheral nerve sheath tumours in neurofibromatosis type 1: tumour-to-liver ratio is superior to an SUVmax cut-off. Eur Radiol 2014; 24: 405-412

46 Combemale P, Valeyrie-Allanore L, Giammarile F et al. Utility of $18 \mathrm{~F}-$ FDG PET with a semi-quantitative index in the detection of sarcomatous transformation in patients with neurofibromatosis type 1. PLoS One 2014; 9: e85954

47 Chirindel A, Chaudhry M, Blakeley J et al. 18F-FDG PET/CT qualitative and quantitative evaluation in NF1 patients for Detection of Malignant Transformation - comparison of early to delayed imaging with and without liver activity normalization. J Nucl Med 2015

48 Kumar AJ, Kuhajda FP, Martinez CR et al. Computed tomography of extracranial nerve sheath tumors with pathological correlation. J Comput Assist Tomogr 1983; 7: 857-865

49 Cohen LM, Schwartz AM, Rockoff SD. Benign schwannomas: pathologic basis for CT inhomogeneities. Am J Roentgenol 1986; 147: 141 - 143

50 Fortman BJ, Kuszyk BS, Urban BA et al. Neurofibromatosis type 1: a diagnostic mimicker at CT. Radiographics 2001; 21: 601-612 